IBT Journal of Business Studies

Volume 14(2), 148-157, 2018

\title{
Power of Training and Development on Employee Retention in Pharmaceutical Organization
}

\author{
M.Usman Aleem \\ Marria Purwani ${ }^{2}$ \\ Usman $\mathrm{Ali}^{3}$ \\ Syed Babar Ali \\ Naeem Bhojani ${ }^{5}$
}

\begin{abstract}
This research is linked to the notion of employee retaining that is severely dependent on the job learning and training. Work learning and training is of the utmost significant factors in keeping the employees retained in the firms or organizations. Training and development is extremely vivacious for confirming effectiveness of the staffs. Though the Pharma firms have overextended and silently considered them as asset i.e. human capital while many are swayed that huge investments in training and development for employee's payoffs. Present study intentions to find out the impact of training beside development program and its advantages to retention of employees. The study includes the theme on which the research is carried out, the study will identify the facts which will result this research about the Power of training and development on employee retention at Pharmevo. The research is based on the local pharmaceutical company. The purpose of this research was based on the interest and urges to analyze that how the pharmaceutical companies retain their employees through training. When organizations make their relation with their employees than the commitment of employees with the organization become stronger. To analyze the relationship and significance among dependent and independent variables, the statistical tool; multiple regression was used for analyzing and deriving the hypotheses. The population of Pharmevo was 350 and the sample size was 282 through Rao soft on which the research is conducted. The applied instrument for the research was Questionnaire; the numbers of items including demographics were 25, however the type of research is quantitative in nature. The used statistical tool was Multiple Regression (SPSS). And the results proved that training do impact on the employee retentions.
\end{abstract}

Key words: Training and development, employee retention, quality working environment, organizational commitment, Employee identification.

1- PAF-KIET, Karachi, Pakistan, M.UsmanAleem:musman@live.com

2- Ilma University. Karachi, Pakistan

3- Ilma University Karachi, Pakistan

4- Ilma University, Karachi, Pakistan

5- FAST, Karachi, Pakistan 


\section{INTRODUCTION}

Staff and Employees i.e. Human capital are vital benefit for firms especially under forceful rivalry. Training and Development purpose allows human capital to set free their adroitness. A thoughtful training program acts like a mean to improve employee abilities as well as skills and achieve well in their work (Umer, 2018). Training, learning as well as development and growth is crucial tactical tool for improving employee or staff or worker performance and that of organizations. The aims is to increase employee's abilities by building them acquire new practices of doing job. Thus, this not only motivates them but build a commitment towards organization (Dhanonjoy \& Humaira, 2017). Resource based View (RBV) is a fundamental Concept which has three of resources and it acts a foundation of competitive advantage which are physical capital, organizational capital and human capital. As we know that, we are in the era of speedy growth where transfer of information and technological complexity is rapid, therefore every firm gets the first two resources to be resources, which impact the competitive advantage and every firm can certainly copy the product and get the first two resources (Ahammad, Tarba, Liu, \& Glaister, 2016). In the era of competitive advantage, to manage these resources is an important task, especially the concluding of the three.

In this development era, where technology has crest importance and it changes rapidly, training has become a requirement for every organization and it is much needed to be a part of a global market. Organizations cannot reply on straight details because to compete in the future they need to develop a strong hold on their employee skills because we are living in the era of productivity and excellence (Tanwar \& Prasad, 2016). Training is defined as "the planned intervention this is designed to enhance the factors of individual job performance" (Ment, 2011). There are organizations who suffer due to lack of training because of unskilled employee. Organizations which focuses on employee training they become successful and can easily retain their employees (Ahammad, Tarba, Liu, \& Glaister, 2016; Ment, 2011).

The concept of training comes from "change through learning". Though it is very necessary for human development. Training is an important factor, through which employee skill and knowledge can be developed. And training is the factor which helps the organization in boosting the retention ratio. For this noteworthy reason, Employee retention and growth is enormously important, because employees are usually judged by their turnover rate. Retaining the employees certifies low turnover. Companies retain their employees by providing them a superior environment in an organization which upturns the growth and performance of an individual employee. (Hassan,Razi,Qamar,Jaffri,\&Suhail, 2013; Tanwar, \& Prasad, 2016).

To create effective employee retention, employer need to work on the environment which reassures current employees to remain employed by having strategies that addresses their assorted needs (Sinha \&Shukla, 2013). Employees are the key assets of organization, if the employee leave the job, the knowledge gap will be created and it directly effects the organization growth. Retaining employees helps in stabilizing the knowledge within the organization. Human capital of an organization added value by training (Chen, 2014; Anis et al., 2011). Training is associated with the skills which are required for the accomplishment of the organizational goals, the skills of enthusiastic which lie in the employee leads to the success and accomplishment (Jehanzeb, Rasheed \& Rasheed, 2013).

Training and development is a crucial problem in the pharmaceutical sector, researchers have said that, it is long term investment on employee skill, it is a tool to polish employees' recent skills for future impacts for becoming more competent for competitive world (Ahmad, 2013). Currently the pharmaceutical industry has been experiencing a high turnover and a decrease in the employee retention. Despite of their efforts of constant effective training and development plans in the pipeline, the employees still tend to leave the organization. On the other hand, the industry maintains its development and employee attraction via ongoing training programs and compensation to improve 
the skills and to help train the employees better in a productive environment (Saleem \& Affandi, 2014). However, Employees are leaving organization due to lack of development in personal grooming and productivity of job requirement to achieve the organizational goals. For that it is essential to prove that the constant training and development in the pharmaceutical industry of Karachi is directly proportional to employee retention and growth. So the problem statement is that the Power of Training and Development helps in retaining the Employee`s at Pharma Organizations Pharmaceuticals.

The purpose of the research is to examine the reason behind the high turnover rate in pharmaceutical industry. The chosen industry is leading industry and it plays an essential in the individual life. To examine the factors which effecting the employee retention and growth is a major issue to study in a particular industry that how pharmaceutical industry can retain their employees and shrinkage their turnover rate through training.

The objective is to understand the major problem related to "Power of training and development on employee retention at Pharma Organizations". To understand and answer this problem research was carried out, in which primary resources such as investigation through questionnaire and secondary resources were used. Another objectives is to understand the impact of quality working environment on employee retention, and essentially, to analyze the need of training for employees which enhance employee retention, and to evaluate the impact of organizational environment on employee retention. This study will be beneficial for Pharma sector, researchers, Scholars, and all other related organization as employee retention is the key problem in the Pharma organizations in today's era. Therefore, it will help organizations to retain employees and implement HR practices.

The research is limited to single city (Karachi), and its Pharma Organizations head office the research also limits in a way that we cannot analyze the number of respondents which are not responding by heart and their real recommendations towards Pharma Organizations. The non-authentic data is also a type of limitation in the research. The research was carried out in limited time duration.

\section{LITERATURE REVIEW}

It is very helpful and of use to review the important of training and development that will give in depth understanding into employee retention with respect to training. Retention is essential aspect of organization which is important to be view on. Training is a helpful to spot which motivate employees to increase performance and achieve organizational goals (Dhanonjoy \& Humaira, 2017). Over the past many years many researchers have explained and researched on training and development and each have a different explanation to retain employees at workplace that how training effects performance and helps the organization to retain them. The focus of this session will be explaining training with respect to employee motivation and how training as factors has a long lasting impact on employee retention. Followed by how training effects work performance and how it impacts an organization as a whole.

In today's world organizations are under consistent pressure to improve productivity and performance for which training is essential aspects through which turnover rate can be reduce. With the help of training and development as it is an essential factor which impact organization commitment and it is also linked with Organization growth and the productivity of an employee (Tanwar, \& Prasad, 2016). Retaining quality performer (employees) increase the organization productivity and it can be easy to strategize the goals of an organization in any direction for achieving them more precisely. For retaining employees, it is very significant that the job must be clearly clarified and labeled in a motivational way (Salman, Ahmad, \& Matin, 2014; Ahammad et al., 2016). Researcher defines the HRM in following words: The process of analyzing and managing an organization's human resource needs to ensure the satisfaction of its strategic objectives. (Sung \& Choi, 2013). Human resource 
management is all about managing the activity, managing the organizations policies in order to achieve the set goals though which company can lead to their triumph.

\section{Employee Retention}

Employee retention is a critical factor of every organization, regarding competitive advantage. For every organization it is a challenging task to retain talented human capital which helps the organization in achieving their goals and it is very important for an organization to use retention strategies for their employees (Anis, Nasir, \& Safwan, 2011). However, it's a crucial aspect on which the focus is very essential.

According to the researcher, employer of the choice is a distinction of a 'war of talent'; this concept is based on the best retention strategy. Employee development, employee management and reward for employees are essential for developing 'Employee Value as well as retaining them too (Tanwar \& Prasad, 2016). Employee value proposition is essential for retaining employees in the pharmaceutical organization. Through developing their skills and managing a good relation among employee's leads to the successful era which is retaining employees easily.

Employee retention is a major problem for HR executives in the pharmaceutical industry or we can say retaining skillful employees are challenging for the chosen industry. The focus of "war of talent" leads to attain best. (Sinha \& Shukla, 2013). Employees are the one who produce or deliver the best service to customers, so if the employees are not committed towards the organization, or not satisfy with the organization environment, doesn't possess high loyalty, the turnover rate goes high which is major problem and the productivity also get effected. Employers need to retain their employees, to provide them a quality environment where they enhance their skills and implement their knowledge, through which the organization can be advanced (Hassan et al., 2013).

Employee retention is not only relating to turnover, it should be focused on how organization motivates their workforce and retains them which will help further to achieved goals and objectives of the organization. To retain quality performers for the betterment of the organization, for which it is very necessary to polish their skills, develop their skills based on new trends. Researcher also states that, it is a vital issue and organization implements different strategies to retain employees (Saleem \& Affandi, 2014). Retaining employees can be done through different factors and it's is essential aspect that organization should retaining employees for the productive workforce and give employee a platform to enrich their skills and develop on the basis of new trends and organizations provide friendly environment and smooth relation between hierarchies which is beneficial for organization productivity and its sustainability. The conceptual framework was adopted from the study of Anis et al., (2011).

\section{Training and Development:}

According to Ampomah (2016) revealed that workers are responsive towards usefulness of training in the firms. He further revealed that workers and staff were motivated by training and it resulted in increase in performance and retention. He suggested that training as well as development of all employees should be dynamically followed and should be obligatory.

Training is basically helpful in formulating the skills, enriching knowledge and helps in modifying the attitudes as well. A practical knowledge, training, is an essential factor to remain in the global market as it is an intended intrusion which boosts the individual factors at job performance which is important to keep it updated. Researcher has defined training as "training actions to impart knowledge skills and attitudes essential to perform job related task. It aims to improve job performance in a direct way" (Mousa, 2003). 
Pharmaceutical industry is that sector, in which companies like Pharma Organziations invest a lot on training which is key aspect through which development takes place. They need employees to be trained and skillful and devoted to the organization. The organization like Pharmevo suffers if their employees are lack of qualities and skills. Organization arranges different training programs for their employees to motivate and enhances their skills in a way that will helpful to the organization (Anis, et al., 2011). Training itself has a significant impact on the organizations productivity because where the employees are trained the organization success and growth level goes high. Organization use training as their strategy for retaining the employee which makes them more dedicated towards their work and enrich employee skills. The training for employees is a huge investment which organization usually do for the growth and productivity for their desired goals. Training and development plays a fundamental role in enhancing employee performance through learning process which includes rules, enhancing skills, knowledge, changing of attitudes and mindsets which leads them to productivity, and increase organization retention ratio high (Din, 2000).

Researcher highlight that increasing employee retention and employee commitment training is that factor which HR manager take in account, for the betterment of the organizations growth because Training is basically a practical knowledge which overcome employee's inefficiencies and enhance the knowledge and boost their skills power in a way to achieve more productivity, which is an important factor leads to success. (Anis et al., 2011; Ahmad, 2013).

\section{Organizational Commitment}

Organizational commitment is all about the level of dedication employee show for its workplace. And it is the active linking to the organization which encourage employee to work and make them devoted towards the organization. It affects the culture of the organization which impact on the other employees who are not in the phase of productivity (Jehanzeb, et al., 2013). Researcher stated that, commitment of employee with an organization plays a significant role which make an active and steadfast relation between employer and employee and make him more ardent towards the work. However other researcher stated that, employees who has a high level of commitment also had a high level of "turnover intellect". This clearly says commitment possesses a significant positive impact on job performance and work commitment (Ruchi Sinha, 2012).

\section{Working Environment}

Organization's environment is a key factor which effect employees in a very extensive way, which enhance the employee's capabilities and commitment towards the organization. Working environment is more effective tool because employees are more satisfied and committed if they get a positive and motivated environment from the organization and good psychological relationship between employers and employee are considerable (Anis et al., 2011). Work environment has a direct effect on employee retention as the employees will work more devotedly and feel pride while working if the organization's environment is approachable (Hassan, 2013). Organization environment impact the employee retention in a way that, organization is a place where different people with different mindset work cumulatively to achieve the goals and for this environment is crucial factor which counts. If the relation of employee with an employer is smooth, friendly, it holds a positive impact on employee commitment towards the organization and the productivity positively effect. For retaining employees, employers need to focus on the environment of the organization which entice positively to the employees. Employees work in a participative environment makes a powerful drive for the organizational success. It is because of their motivation and commitment to the organization which leads them to success (Eric, 2012). The conceptual framework was adopted from a study conducted by Anis and other researchers (Anis, Rehman, Nasir, \& Safwan, 2011) 


\section{Formation of Hypothesis: Hypothesis One}

Training and development assist employees in creating positive inputs which are essential to the accomplishment of organization with regard to good performance on their jobs. Training and Learning is much more important in attaining the organizational goals and objectives by keeping the interest of workers or employees and organization (Tetteh, Sheng, Yong, \& Narh, 2017)

Training and development is an essential factor to remain in the global market as it is an intended intrusion which boosts the individual factors at job performance which is important to keep it updated. The organization like Pharmevo suffers if their employees are lack of qualities and skills. Organization arranges different training programs for their employees to motivate and enhances their skills in a way that will helpful to the organization. (Altmann, 2015). Training itself has a significant impact on the organizations productivity because where the employees are trained the organization success and growth level goes high. Organization use training as their strategy for retaining the employee which makes them more dedicated towards their work and enrich employee skills.

Training and development plays a fundamental role in enhancing employee performance through learning process which includes rules, enhancing skills, knowledge, changing of attitudes and mindsets which leads them to productivity, and increase in high ratio of organizational retention (Abdullah \& Nazmul Hasan, 2017; Aruna \& Anitha, 2015). However, Training and development is that factor which has a high impact on employee retention because when organization give training to their employees, they keeps their strategic goals in mind which can only be achieved by the loyal and devoted employees of the organizations (Aruna \& Anitha, 2015). This leads to the first hypothesis formation that is as follows:

$\mathbf{H}_{\mathrm{A} 1}$ : Training and development that builds a sense of debt to the organization will lead to an increase in Employee retention.

Ho1: Training and development that builds a sense of debt to the organization will not lead to an increase in Employee retention.

\section{Hypothesis Two:}

HA2: The high quality working environment is positively related to employee retention.

$\mathbf{H}_{\mathbf{0} 2}$ : The high quality working environment is not positively related to employee retention.

\section{METHODOLOGY}

The study was empirical in nature. A research design has been considered for carried out this descriptive study. This Quantitative based study used statistical tool which is multiple regression analysis and was used by various researchers in similar studies. Researcher used the multiple regression analysis as statistical tool to analyze the relationship between dependent and independent variables.

The total population of Pharmevo consists of 350 Managers. Sample size for the study is calculated through Rao soft (sample size calculator). The sample size for the study is limited to 282 respondents and pilot testing was done on 50 respondents belonging to the designation Managers, Assistant Managers and Supervisors. The questionnaire is developed from the previous studies. All the items in the questionnaire are divided on the basis of the variables. Each variable is given the allocation of 5 items, and 5 questions are from demographics section, which makes the questionnaire in total of 25 questions. However, while designing the questionnaire, the researcher has followed the eight steps of development process provided by Churchill (Glibert Churchill, 1979). Likewise, Cronbach alpha was 
0.796 , this value is greater than 1 . This means that the questionnaire is reliable for data collection. For the literature review secondary sources included emerald journals, international journals of human resource management, various books and web pages were seen. While primary data collected through questionnaire.

\section{Analysis of Findings}

It was necessary to find the age and gender of the employees, as well as their experience at Pharma Organizations.

\section{Gender, Age and Experience}

According to table $4.1,67 \%$ employees participated were males and $33 \%$ were females.

\begin{tabular}{|c|c|c|}
\hline Gender & Frequency & Percentage (\%) \\
\hline Male & 188 & 67 \\
\hline Female & 94 & 33 \\
\hline Total & $\mathbf{2 8 2}$ & $\mathbf{1 0 0}$ \\
\hline
\end{tabular}

Figure. 1(a). Gender of Employees

The respondents were divided into various age group, $35 \%$ employees fall under the age of above 40 , $30 \%$ lies between $20-30$ age group, $35 \%$ employee were from the age group of $30-40$.

\begin{tabular}{|c|c|c|}
\hline Age & Frequency & $\mathbf{( \% )}$ \\
\hline Above 40 & 98 & 35 \\
\hline $30-40$ Years & 100 & 35 \\
\hline 20-30 Years & 84 & 30 \\
\hline Below 20 & 0 & 0 \\
\hline Total & $\mathbf{2 8 2}$ & $\mathbf{1 0 0}$ \\
\hline
\end{tabular}

Figure. 1(b) Age of Employees

In Experience at Pharma Organizations, $3 \%$ of employees having below 5 years' experience at Pharma Organizations, whereas $25 \%$ having the experience fall under $5-10$ years, $43 \%$ of employees having 10-15 years of experience and $29 \%$ of total sample size fall above 15 years of experience.

\section{Detailed Analysis}

Hypothesis one: Training that builds a sense of debt to the organization will lead to an increase in Employee retention.

\begin{tabular}{|l|c|c|c|c|}
\hline \multirow{3}{*}{ Model } & \multicolumn{3}{|c|}{ Model Summary } \\
\cline { 2 - 5 } & $\mathbf{R}$ & R Square & $\begin{array}{c}\text { Adjusted R } \\
\text { Square }\end{array}$ & Std. Error of the Estimated \\
\hline $\mathbf{1}$ & 0.540 & 0.453 & 0.603 & 0.325 \\
\hline
\end{tabular}

\begin{tabular}{|l|l|c|c|c|c|c|}
\hline \multicolumn{7}{|c|}{ ANOVA } \\
\hline Model & & $\begin{array}{c}\text { Sum of } \\
\text { Squares }\end{array}$ & df & $\begin{array}{c}\text { Mean } \\
\text { Square }\end{array}$ & F & Sig. \\
\hline $\mathbf{1}$ & Regression & 5.115 & 1 & 3.517 & 19.485 & 0.002 \\
\hline & Residual & 31.171 & 95 & 0.390 & & \\
\hline & Total & 36.296 & 96 & & & \\
\hline
\end{tabular}

Interpretation of Hypothesis one: The Null hypothesis 3 reflects that Training that builds a sense of debt to the organization will not lead to an increase in Employee retention. According to the results analysis through primary data collection which shows that the Employee Identification is creating 
$54.0 \%$ impact on employee retention. The association between the Sense of Debt and employee retention is $45.3 \%$. The company would focus on Sense of Debt then the employee retention may create positive reflection of $60.3 \%$. In the analysis DF (degree of freedom) for regression shows as 1 with the mean of 3.517 . The ratio of $F(F)$ is 19.485 which indicate that the every 20 th value could be different then the whole observation. According to the analysis the numerical value of Significant is 0.002 which indicates that the relation of Sense of Debt and employee retention are highly significant so, on the basis of observation, we REJECT our null hypothesis.

Hypothesis Two: The high quality working environment is positively related to employee retention.

\begin{tabular}{|c|c|c|c|c|}
\hline \multirow{2}{*}{ Model } & \multicolumn{3}{|c|}{ Model Summary } \\
\cline { 2 - 5 } & R & R Square & Adjusted R Square & Std. Error of the Estimated \\
\hline $\mathbf{1}$ & 0.403 & 0.630 & 0.594 & 0.545 \\
\hline
\end{tabular}

\begin{tabular}{|l|l|c|c|c|c|c|}
\hline \multicolumn{7}{|c|}{ ANOVA } \\
\hline Model & & Sum of Squares & df & Mean Square & F & Sig. \\
\hline $\mathbf{1}$ & Regression & 6.447 & 1 & 6.447 & 18.459 & 0.001 \\
\hline & Residual & 33.181 & 95 & 0.349 & & \\
\hline & Total & 39.629 & 96 & & & \\
\hline
\end{tabular}

Interpretation of Hypothesis two: The Null hypothesis 1 reflects that the high quality of working environment is not possibly related to employee retention. According to the results analysis through primary data collection which shows that the working environment is creating $40.3 \%$ impact on employee retention. The association between the working environment and employee retention is $63 \%$. The company would focus on working environment then the employee retention may create positive reflection of 59.4\%. In the analysis DF (degree of freedom) for regression shows as 1 with the mean of 6.447 . The ratio of $F(F)$ is 18.459 which indicate that the every $19^{\text {th }}$ value could be different then the whole observation. According to the analysis the numerical value of Significant is 0.001 which indicates that the relation of working environment and employee relation are highly significant so, on the basis of observation, we REJECT our null hypothesis.

\section{CONCLUSION}

Training is a significant and imperious tool for the Pharma's to reinstate the loyalty, retention and performance. In other words, it is equally important and valuable for both staff as well as firms. The study was carried out on employee retention and Power of training \& development at Pharma Organziations in Karachi. The research was based on a Local Pharmaceutical Companies. The main focus of the organizations is towards the training for their employees. Organizations provide training to the employees for making them to enrich their skills and stand as a competitively in the market. To keep employee, retain in the organization, organization need to keep the working environment calm and friendly so that employees have their commitment towards the organization as extraordinary.

The study is a type of quantitative research in nature and the researcher used convenience sampling and snow ball sampling technique where the sample size was 282 (Rao soft) including Managers, Assistant Managers. The research includes middle management people from Pharmevo. However, in the research the questionnaire's pilot testing was also dependent on the result of reliability which shows the significance value of the Cronbach Alpha 0.796. The statistical tool used for the research by the researcher was multiple regression analysis, as used in the related previous studies. The questionnaire is developed from the previous studies about the employee retention with respect to training and development. The analysis of the research declares the significant impact on employee retention via training and development. Two hypotheses were developed where employee retention was dependent variable. The derived hypothesis where from the derived variables of the research, and all 2 hypotheses were accepted. All hypotheses relationships were found to be positive and significant. These results were in line with the previous studies results conducted by Tanwar and Prasad (2016); 
Abdullah and Nazmul Hasan (2017); Chen (2014) as well as Saleem \& Affandi (2014).

One thought-provoking outcome from this research was recognized that there is a vital impact on the job performance of employees through training and Development which leads to motivated employees and eventually a retained and loyal internal customer. So it is clear that training is very much important for everyone in the organization. Though employees were motivated and satisfied and not willing to move or switch due to positive feeling but the organization should evaluate them continuously for understanding their learning levels.

\section{Applied Implication as well as Recommendations}

The findings of this study will be valuable for Pharmevo as well as other organizations to know that learning and training practice can be shaped into a retention policy and strategy. This research learns the perception of staff or managers or employees about learning as well as training practices, as when staff or managers or employees are attracted to stay with a firm. There could be a opportunity that if a firm or organization fulfills the managers or employees necessity's regarding improving current skills and preparing them for future challenges, the rate of retention will be improved and boosted. This investigation can benefit the firms or organization for building a repute of a learning firm; it can also become a favorite organization or firm for new graduates as well as employees and people from same organization too.

\section{REFERENCES}

Ahammad, M. F., Tarba, S. Y., Liu, Y., \& Glaister, K. W. (2016). Knowledge transfer and cross-border acquisition performance: The impact of cultural distance and employee retention. International Business Review, 25(1), 66-75.

Anis, A., Nasir, A., \& Safwan, N. (2011). Employee retention relationship to training and development: A compensation perspective. African journal of business management, 5(7), 2679.

Ampomah, P. (2016). The Effect of Training and Development on Employee Performance in a Private Tertiary Institution in Ghana"- Case Study: Pentecost University College (Puc)Ghana,Asian Journal of Social Sciences and Management Studies,3(1), 29-33.

Altmann, R. (2015). A new vision for older workers: retain, retrain, recruit. London: Department for Work and Pensions.

Aruna, M., \& Anitha, J. (2015). Employee retention enablers: Generation Y employees. SCMS Journal of Indian Management, 12(3), 94.

Chowdhury Abdullah Al Mamun and Nazmul Hasan (2017). Factors affecting employee turnover and sound retention strategies in business organization: a conceptual view. Problems and Perspectives in Management, Volume 15, Issue 1, 2017.

Dr. Dhanonjoy Kumar \& Humaira Siddika (2017). Benefits of Training and Developmnet program on employees ` performance: A study with special reference to banking sector in Bangladesh.

Gilbert A. Churchill, Jr., Journal of Marketing Research, 16:1. (Feb., 1979), pp. 64-73).

MENT, T. N. A. (2011). Training need assessment: A critical study. International Journal of Information Technology, 4(1), 263-267.

Hassan, W., Razi, A., Qamar, R., Jaffir, R., \& Suhail, S. (2013). The effect of training on employee retention. Global Journal of Management And Business Research.

Jehanzeb, K., Rasheed, A., \& Rasheed, M. F. (2013). Organizational commitment and turnover intentions: impact of employee's training in private sector of Saudi Arabia. International Journal of Business and Management, 8(8), 79.

Chen, M. (2014). The effect of training on employee retention. In 2014 International Conference on Global Economy, Commerce and Service Science (GECSS-14). Atlantis Press.

Saleem, M., \& Affandi, H. (2014). HR Practices and Employees Retention, an empirical analysis of Pharmaceutical sector of Pakistan. IOSR Journal of Business and Management, 16(6), 111- 
116.

Ahmad, U. (2013). Impact of training on employee retention. Case Business School.

Salman, A., Ahmad, N., \& Matin, F. (2014). Factors affecting on employees retention in banking sector: An investigation from Karachi. European Journal of Business and Management, Vol.6, No.37,

Sung, S. Y., \& Choi, J. N. (2014). Do organizations spend wisely on employees? Effects of training and development investments on learning and innovation in organizations. Journal of organizational behavior, 35(3), 393-412.

Sinha, D., \& Shukla, S. K. (2013). A study of Employee Retention in the Pharmaceuticals sector in Dehradun City. International Journal of Education and Psychological Research, 2(1), 30 39.

Tetteh, S., Sheng, C., Yong, D., \& Narh, C. THE IMPACT OF TRAINING AND DEVELOPMENT ON EMPLOYEES'PERFORMANCE (A CASE STUDY OF MILLICOM GHANA LIMITED-TIGO). (2017). International Journal of Information Research and Review, 04(01), 3482-3487.

Masadeh, M. (2012). Training, education, development and learning: what is the difference? European Scientific Journal, ESJ, 8(10).

Morgan, G. A., Leech, N. L., Gloeckner, G. W., \& Barrett, K. C. (2004). SPSS for introductory statistics: Use and interpretation. Psychology Press.

Umer Ahmad. (2018). Impact of Training on Employee Retention. Available from: https://www.researchgate.net/publication/263808540_Impact_of_Training_on_Employee Retention [accessed July, 042018 ].

Tanwar, $\bar{K}$., \& Prasad, A. (2016). Exploring the relationship between employer branding and employee retention. Global Business Review, 17(3_suppl), 186S-206S.

Taraban, R., Kerr, M., \& Rynearson, K. (2004). Analytic and Pragmatic Factors in College Students' Metacognitive Reading Strategies. Reading Psychology, 25(2), 67-81. 